\title{
Metronidazole in Periodontitis*
}

\section{Clinical and Bacteriological Results after 15 to 30 Weeks}

\author{
W. J. Loesche,† S. A. Syed,‡ E. C. Morrison,§ G. A. Kerry, ॥ \\ T. Higgins $\pi$ and J. Stoll ${ }^{\star \star}$
}

Accepted for publication 10 August 1983

\begin{abstract}
THE STATISTICAL ASSOCIATION of certain anaerobic organisms such as black pigmented bacteroides (BPB) species and spirochetes with clinical signs of active periodontitis, i.e. bleeding upon probing and bone loss, suggests that the lesions may actually reflect a "specific infection" involving these or unidentified species. All the known oral species of BPB and spirochetes are anaerobes which suggests that antimicrobial treatment directed specifically against anaerobes might be effective in periodontal therapy. In this report, the short-term results of metronidazole treatment plus mechanical debridement in patients with extensive periodontal disease and of a double-blind clinical study in which metronidazole plus mechanical debridement is compared to placebo plus mechanical debridement are described. The findings indicate that 1 week of systemic metronidazole can optimize the clinical reduction of pockets and increase the apparent attachment in periodontitis patients who receive concurrent mechanical debridement of their root surfaces. In patients with extensive clinical involvement, metronidazole resulted in a significant reduction in the number of sites exhibiting pocket depths and attachment loss $\geq 7 \mathrm{~mm}$. When metronidazole plus mechanical debridement was compared with placebo plus mechanical debridement in a double-blind study, the metronidazole patients exhibited a significant improvement in those sites initially $\geq 7 \mathrm{~mm}$. The beneficial effect of the metronidazole was associated with a significant and sustained reduction of certain anaerobic organisms such as Bacteroides gingivalis and the large spirochetes. These data indicate that treatment aimed specifically toward the anaerobic component of the plaque flora can be associated with impressive clinical improvements 15 to 30 weeks after the initiation of treatment.
\end{abstract}

Periodontal disease is the foremost cause of tooth loss in adult populations. ${ }^{1}$ In recent years the essential role of bacterial plaque in initiating and propagating a host inflammatory response in the periodontal tissues has been documented both in experimental gingivitis in humans ${ }^{2.3}$ and in periodontitis in animals. ${ }^{4-6}$ Moreover there appears to be an element of bacterial specificity in these periodontal infections as spirochetes ${ }^{7,8}$ and black pigmented bacteroides (BPB) ${ }^{9,10}$ are signifi-

\footnotetext{
* University of Michigan School of Dentistry, University of Michigan School of Medicine. This research was supported by Public Health Service grants DE 02731 and DE 06030 from the National Institute of Dental Research.

$\dagger$ Professor of Dentistry and Microbiology, University of Michigan School of Dentistry, Ann Arbor, MI 48109.

$\ddagger$ Research Scientist, Dental Research Institute.

$\S$ Associate Research Scientist, School of Dentistry.

\| Professor of Dentistry, School of Dentistry.

I Visiting Assistant Professor, School of Dentistry.

** Research Assistant, School of Dentistry.
}

cantly elevated in plaques removed from sites of active periodontitis, and Actinobacillus actinomycetemcomitans is either present, or in high proportions in plaques taken from sites of bone loss in patients diagnosed as exhibiting localized juvenile periodontitis ${ }^{11,12}$ or rapidly progressing periodontitis. ${ }^{13}$ Peripheral blood taken from periodontal patients reveals significant increases in specific antibodies to the above organisms. ${ }^{14,15}$

The statistical association of certain organisms with clinical signs of active disease, i.e., bleeding upon probing and bone loss, suggests that the observed lesions may actually reflect a "specific infection" involving these or possibly unidentified bacterial species. These observations led to the formulation of the specific plaque hypothesis (SPH), which views certain plaques as being periodontopathic because they are colonized and/or dominated by one or more bacterial types. These bacterial types are presumed, on the basis of association-type data and animal studies, to be responsible for a measurable amount of periodontal tissue 
destruction. ${ }^{16}$ The SPH does not state that these bacterial species are responsible for all forms of periodontal disease, but rather that they are responsible for a measurable amount of the tissue destruction with the expectation that this amount will be biologically and clinically significant. Implicit in the SPH is the concept of nondisease-associated plaque. ${ }^{17}$ For practical purposes the nondisease-associated plaque is simply plaque which is not colonized and/or dominated by the known or suspected periodontopathogens. It can be readily identified by microscopic examination as plaque that is dominated by cocci and nonmotile rods. ${ }^{7.18}$

$\mathrm{BPB}$ species, such as Bacteroides gingivalis and Bacteroides intermedius, and spirochetes are invariably elevated in periodontopathic plaques to the extent that if they are not contributors to the pathogenesis, they at least are diagnostic indicators of active disease. ${ }^{10,19}$ All the known oral species of BPB and spirochetes are anaerobes which suggests that antimicrobial treatment directed specifically against anaerobes might be effective in periodontal therapy. The efficacy of the antiprotozoa agent metronidazole in acute necrotizing gingivitis (ANUG) ${ }^{20}$ led to the discovery that metronidazole has a unique bacteriocidal action against anaerobes. ${ }^{21}$ Subsequently it was shown that the curative effect of metronidazole in ANUG was associated with the significant and sustained suppression of spirochetes and $B$ intermedius in plaque samples removed from the ANUG lesions. ${ }^{22}$

This action of metronidazole against the type of anaerobes associated with active periodontitis led to a clinical trial of metronidazole in selected periodontitis patients. ${ }^{10}$ A 1-week treatment of metronidazole with and without scaling was associated with a sustained suppression of $B$ gingivalis and spirochetes for periods of 6 months or more. In addition the sites with an initial probing depth of $6 \mathrm{~mm}$ or more exhibited a probing depth reduction of $2 \mathrm{~mm}$ or more and an apparent attachment gain of $1.5 \mathrm{~mm} .{ }^{10}$ In a study conducted in Sweden, metronidazole, given for three 2-week periods, each separated by an interval of 8 weeks, was found to give clinical and bacteriological results comparable to that obtained by rigorous mechanical debridement which was delivered in a series of four visits. ${ }^{23}$ Both of these clinical studies indicate that metronidazole may be an antimicrobial agent of therapeutic value in the treatment of active periodontal infections.

In the present report, the short-term results of metronidazole treatment plus mechanical debridement in patients with advanced periodontal disease are presented, and a double-blind clinical study in which metronidazole plus mechanical debridement is compared to placebo plus mechanical debridement is described.

\section{MATERIALS AND METHODS}

Individuals with clinical evidence of bone loss were recruited into the study after being diagnosed as having an anaerobic periodontal infection, i.e., ten per cent spirochetes in one or more subgingival plaque samples. They were told of metronidazole's spectrum of activity against anaerobes and that we were evaluating whether metronidazole would be efficacious in the treatment of anaerobic periodontal infections. Patients were advised of the mutagenicity of metronidazole in bacterial systems,${ }^{24}$ and of the potential adverse reactions of metronidazole with alcohol consumption in some individuals. They were also told that in certain, but not all, rodent species, lifetime administration of high dosages of metronidazole, i.e., up to $0.6 \%$ of the diet, was associated with both tumors and longevity. ${ }^{25.26}$ The lifetime dosage used in some of the animal studies ${ }^{26}$ was about 3,500 times the total dosage used in the present investigation. This therapeutic dosage for humans has not been associated with human tumors ${ }^{27,28}$ or with birth defects. ${ }^{29.30}$ They were told that we were investigating this usage of metronidazole under an investigational new drug exemption from the Food and Drug Administration (FDA).

Metronidazole-Mechanical Groups. Forty patients with multiple sites of periodontal bone loss were assigned to one of two groups depending on the initial severity of their periodontal condition. If the number of sites with bone loss was extensive, i.e., an average of 20 or more sites per patient with apparent attachment loss of $7 \mathrm{~mm}$ or more, the patients were placed in an advanced disease group which received both metronidazole and meticulous root surface debridement. If the number of sites with bone loss was moderate, i.e. an average of about 10 sites per patient with attachment loss of $7 \mathrm{~mm}$ or more, the patients were placed into a double-blind group. The patients in the double-blind group received the same meticulous root surface debridement as the advanced disease group, but had a $50 \%$ chance of receiving either metronidazole or a placebo medication. All patients were given 21 tablets containing either metronidazole or placebo $(250 \mathrm{mg})$ (both metronidazole, Flagyl ${ }^{\circledR}$, and placebo were gratuitously provided by the G. D. Searle Co) at the first session of root scaling with instructions to take three tablets a day for 7 days. Compliance was monitored by history.

This method of patient assignment resulted in three groups who each received all the mechanical debridement and oral hygiene instruction that was deemed necessary to bring them successfully through the hygienic phase of periodontal therapy. The groups differed in that a more severely diseased set of individuals was known to have received metronidazole (metronidazolemechanical group), whereas a less diseased set of individuals was randomly assigned in a double-blind fashion to either metronidazole (double-blind, metronidazole-mechanical group) or to placebo (double-blind placebo-mechanical group).

Bacteriological Procedures. Subgingival plaque was removed from one periodontal pocket per quadrant in 
each patient for a total of four samples per patient. The sites chosen appeared from $\mathrm{x}$-ray examination to be the most severely involved in each quadrant and were usually about molar teeth. The supragingival plaque about the sample site was removed with a curette and discarded. The root surface was then scaled and the adherent plaque on the scaler tip was transferred to a vial containing $0.5 \mathrm{ml}$ of reduced transport fluid (RTF) without EDTA. ${ }^{31}$ The plaque sample was immediately placed within the anaerobic chamber and after dispersing for 20 seconds with a Vortex mixer, a $50 \mu \mathrm{l}$ aliquot was removed for microscopic examination. The remaining sample was diluted to $4 \mathrm{ml}$, sonically dispersed for 20 seconds with a Kontes sonifier,* serially diluted in RTF and plated automatically with a spiral plater $\dagger$ on a variety of selective and nonselective media. The method enabled us to obtain microscopic and cultural data on the same plaque sample.

The total anaerobic count, the count of BPB species, Capnocytophaga species, Fusobacterium nucleatum and Actinomyces odontolyticus were obtained by identification of their distinctive colonies on enriched trypticase soy agar (ETSA). ${ }^{32}$ Either all or representative colonies of BPB were identified as $B$ gingivalis, $B$ intermedius and Bacteroides melaninogenicus initially by their ability to use glucose, to hydrolyze esculin and to produce indole, ${ }^{22}$ and subsequently by a rapid test using chromogenic enzyme substrates. ${ }^{33,34}$ Actinomyces viscosus and Actinomyces naeslundii were differentiated by catalase activity of colonies growing on a selective GMC agar. ${ }^{35}$ The total count of facultative organisms, Streptococcus sanguis and Streptococcus mutans were obtained from growth on ETSA agar containing $2 \%$ sucrose and $20 \mu \mathrm{g} / \mathrm{ml}$ of metronidazole, which was incubated anaerobically. Veillonella colonies were enumerated on a medium containing MM10 base, minus blood but supplemented with lactate, vancomycin and a $0.004 \%$ bromocresol purple indicator.

Ten $\mu \mathrm{l}$ of the aliquot removed for microscopic examination was placed on a glass slide, covered with a $22 \times 30 \mathrm{~mm}$ cover slip, sealed and viewed by dark-field microscopy. Either 200 organisms or the number of organisms in 20 high power fields (HPF) were enumerated, depending on which event occurred first. The single cells were identified as spirochetes, selenomonads, motile rods, fusiforms, nonmotile rods or cocci. ${ }^{7,22}$ The spirochetes were further subdivided into large, intermediate and small size spirochetes.

Clinical Evaluation. All teeth, including molars with furcation involvement, were scored for pocket depth (probing depth) and loss of attachment using procedures previously described. ${ }^{36}$ All readings were obtained by one individual (ECM), who was not aware of the medications given to participants in the double-blind study.

\footnotetext{
* Kontes Glass Co, Vineland, NJ.

† Spiral Systems, Inc, Cincinnati, OH.
}

Statistical Analysis. The counts for each organism enumerated culturally and microscopically were recorded on forms suitable for computer processing.

The proportions of these organisms were calculated by dividing the viable count of the specific organism by the total viable count on the ETSA agar plate in the case of the cultural data, and by dividing the microscopic count of the specific organism by the total microscopic count in the case of the microscopic data. If there were less than 20 colony-forming units (CFU) on the ETSA plate or in the microscopic count, no proportions were calculated. This was to eliminate distortions of the data which can occur when the denominator is very low, as can be the case for microscopic counts following treatment.

The total counts and the proportions of organisms in each cultural and microscopic sample were statistically analyzed using the computer programs available in the Michigan terminal system. Comparisons between the placebo and metronidazole samples in the double-blind study were analyzed by the parametric student $t$ test. The effect of metronidazole or placebo plus mechanical debridement on bacterial and clinical parameters within each group was evaluated by the paired $t$ test.

\section{RESULTS}

All patients reported that they used the entire supply of medication that was provided them. A few patients noted a metallic taste. Otherwise no complaints were recorded. Some patients were unable to, or did not, return for clinical examinations of pocket depth and attachment loss that were specially scheduled following completion of the hygienic phase of therapy. This meant that in some cases we had posttreatment bacteriological data for patients in whom we had no posttreatment clinical measurements. We chose to analyze all the available bacteriological data within a group, but to restrict our bacteriological comparisons between groups to only those subjects for whom we had complete clinical data.

The patients assigned to the known metronidazole group initially had significantly more sites per dentition that had pocket depths or attachment loss greater than $7 \mathrm{~mm}$, than did those patients assigned to the doubleblind groups, (Figs. 1 and 2). This increased clinical involvement was the justification for placement of these patients into a distinct group.

These advanced-disease patients responded favorably to treatment in that 15 to 30 weeks after usage of metronidazole and about 10 to 20 weeks after the completion of the mechanical debridement of the root surfaces, the number of pocket sites per patient that were $\geq 7 \mathrm{~mm}$ had decreased from 22.8 to 4 (mean values) and the number of sites with attachment loss $\geq 7 \mathrm{~mm}$ decreased from 25.3 to 14.6 (mean values). The magnitude of this change was greater than that observed in the double-blind groups (Figs. 1 and 2). 


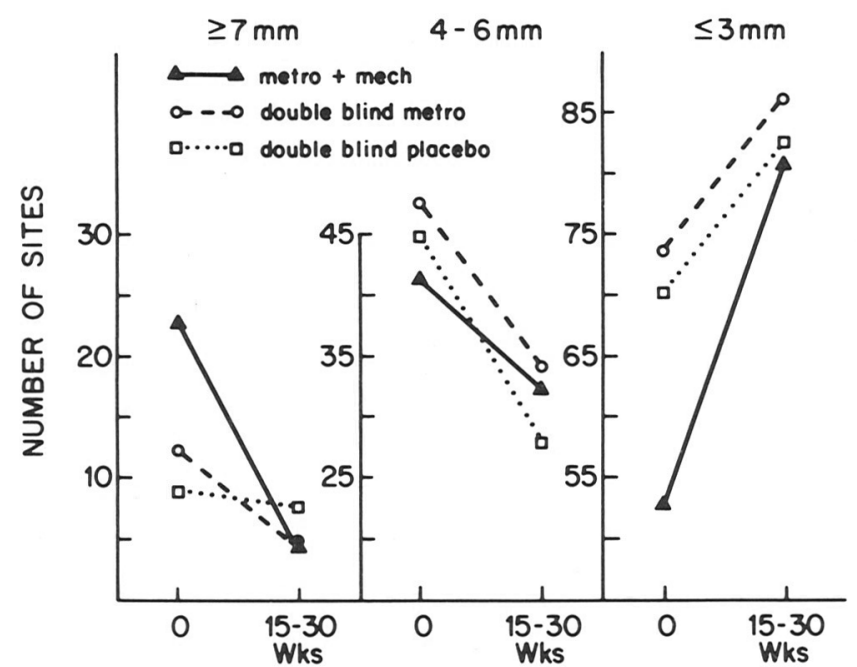

Figure 1. Frequency distribution of number of sites with pockets.

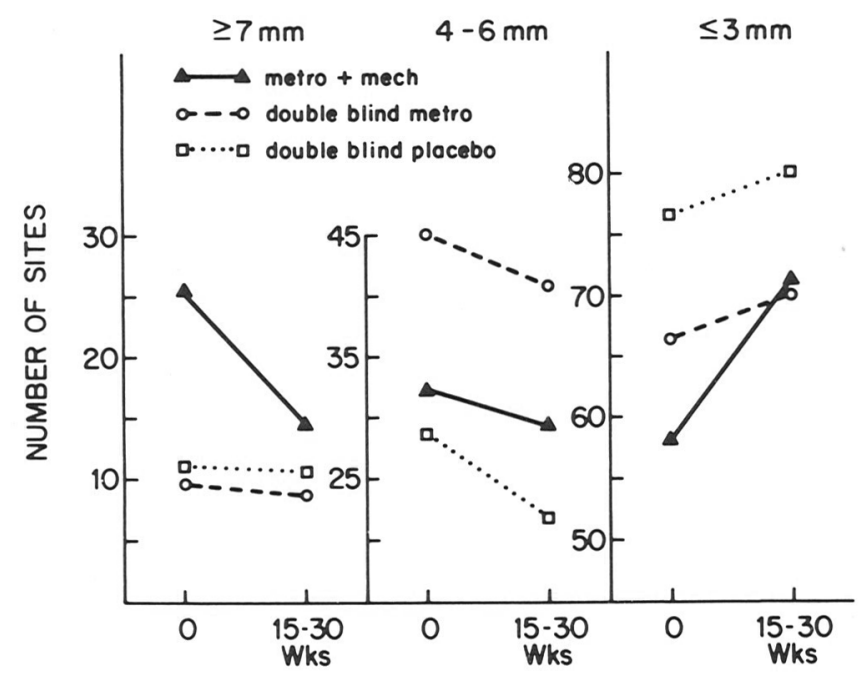

Figure 2. Frequency distribution of number of sites with attachment loss.

Treatment also resulted in a pronounced increase in the number of sites in which the pocket depths and attachment loss were $\leq 3 \mathrm{~mm}$ (Figs. 1 and 2).

Metronidazole treatment in the double-blind patients reduced the number of pockets that were $\geq 7 \mathrm{~mm}$ from 12 per patient to 4 per patient (mean values) and the number of sites with attachment loss $\geq 7 \mathrm{~mm}$ from 9.7 to 8.8 (mean values). Placebo treatment reduced the number of pockets that were $\geq 7 \mathrm{~mm}$ from 8.9 per patient to 7.7 per patient (mean values) and the number of sites with attachment loss $\geq 7 \mathrm{~mm}$ from 11.3 to 10.1 (mean values) (Figs. 1 and 2).

The magnitude of probing depth (pocket) reduction and the apparent attachment gain in each site found in these double-blind patients were determined. In sites that were initially 4 to $6 \mathrm{~mm}$ in depth or which exhibited 4 to $6 \mathrm{~mm}$ attachment loss, both metronidazole and placebo treatments caused about a $1-\mathrm{mm}$ decrease in pocket depth and about a $0.3 \mathrm{~mm}$ apparent gain in attachment (Table 1). The slight advantage observed in

the metronidazole group was not significant. However, in the deeper pockets and in sites with greater attachment loss, there was a significant advantage associated with metronidazole treatment (Table 1). Thus while placebo plus mechanical treatment reduced pocket depth $1.6 \mathrm{~mm}$ and increased attachment gain by 0.3 $\mathrm{mm}$, the metronidazole plus mechanical treatment reduced pocket depth by $3.2 \mathrm{~mm}$ and increased apparent attachment gain by $1.4 \mathrm{~mm}$.

The reasons for the apparent clinical effectiveness of the various treatments were sought in the analysis of the bacterial composition of the subgingival plaque in the most clinically diseased site per quadrant. All treatments reduced the levels of bacteria in the plaque samples as judged by total viable counts on anaerobically incubated ETSA plates, and by the number of bacteria observed per high-power field (HPF) of the darkfield microscope (Table 2). The high viable counts noted posttreatment in the double-blind metronidazole group reflected a few very high counts that raised the mean value, but not the median value. These outlying

Table 1

Effect of Metronidazole or Placebo Treatment Superimposed Upon Instrumentation-Double Blind Study*

\begin{tabular}{|c|c|c|c|c|}
\hline \multirow{2}{*}{$\begin{array}{l}\text { Original measure- } \\
\text { ment }\end{array}$} & \multicolumn{4}{|c|}{ Change in measurement } \\
\hline & $\begin{array}{l}\text { Metronida- } \\
\text { zole }\end{array}$ & & Placebo & $\begin{array}{l}\text { Differ- } \\
\text { ence }\end{array}$ \\
\hline \multicolumn{5}{|l|}{ Pocket depth } \\
\hline $4-6 \mathrm{~mm}$ & $-1.19 \mathrm{~mm}$ & & $-1.05 \mathrm{~mm}$ & $0.14 \mathrm{~mm}$ \\
\hline$>6 \mathrm{~mm}$ & -3.19 & $0.03 \uparrow$ & -1.55 & 1.64 \\
\hline \multicolumn{5}{|l|}{ Attachment distance } \\
\hline $4-6 \mathrm{~mm}$ & +0.38 & & +0.28 & 0.10 \\
\hline$>6 \mathrm{~mm}$ & +1.42 & $0.05 \dagger$ & +0.23 & 1.19 \\
\hline No. of patients & 7 & & & \\
\hline
\end{tabular}

* Results are 2 to 4 months after completion of hygienic phase. $\dagger$ Difference between groups is significant, $t$ test.

Table 2

Effect of Metronidazole or Placebo Plus Mechanical Debridement on Size of Pocket Flora

\begin{tabular}{|c|c|c|c|}
\hline \multirow{2}{*}{ Treatment regimen* } & \multirow{2}{*}{ Pretreatment } & \multicolumn{2}{|c|}{ Posttreatment } \\
\hline & & $0-2$ wks & $15-30 \mathrm{wks}$ \\
\hline
\end{tabular}

Total Count $\times 10^{6} \%$

plaque

Metro + Mech

DB Metro + Mech

DB Placebo + Mech

$\%$ Facultative

Metro + Mech

DB Metro + Mech

DB Placebo + Mech

Microscopic Counts/ HPF

Metro + Mech

DB Metro + Mech

DB Placebo + Mech

\begin{tabular}{l}
\hline 31.3 \\
\hline 24.1 \\
31.1 \\
\hline $19.8{ }^{\mathrm{P}}$ \\
\hline $42.0^{\mathrm{P}}$ \\
33.3 \\
\\
15.2 \\
20.9 \\
19.4
\end{tabular}

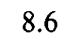

\section{1}

15.5

91.8

$63.3^{\mathrm{P}}$

53.4

5.8

6.9

7.6

* Metro = metronidazole; Mech $=$ mechanical; $\mathrm{DB}=$ doubleblind.

$\mathrm{P}=$ paired $t$ test; values with these superscripts or $\square$ are significantly different from other values in row. 
values could be due to the non- or underutilization of the metronidazole by certain participants.

The patients with advanced disease differed initially from the double-blind patients in having a reduced percentage of facultative bacteria in their plaques (Table 2). Treatment in these patients resulted in a significant increase in the proportions of facultative bacteria that was still evident 15 to 30 weeks after the administration of metronidazole. The double-blind patients also exhibited an increase in the proportions of facultative bacteria as a result of treatment, but this increase was not significant, probably due to the relatively high initial proportions of facultative organisms in these patients (Table 2).

The effect of the various treatments on selected cultivable anaerobes is shown in Table 3. All treatments resulted in a decrease in the proportions of $B$ intermedius in the immediate postmedication period (Table 3 ). The reductions observed in the metronidazole groups were still evident 15 to 30 weeks after treatment, whereas the reduction in the placebo group did not persist. All treatments also reduced the proportions of $B$ gingivalis, but only those in the metronidazole groups were significant. The proportions of $F$ nucleatum declined significantly following medication in the known metronidazole group but then significantly increased 15 to 30 weeks later. The proportions of $A$ odontolyticus increased following treatment in all groups (Table 3 ).

The effect of the treatments on selected facultative

Table 3

Effect of Metronidazole and/or Mechanical Debridement on Subgingival Proportions of Selected Anaerobes

\begin{tabular}{|c|c|c|c|}
\hline \multirow{2}{*}{ Treatment regimen* } & \multirow{2}{*}{$\begin{array}{c}\text { Pretreat- } \\
\text { ment }\end{array}$} & \multicolumn{2}{|c|}{ Posttreatment } \\
\hline & & $0-2$ wks & $15-30 \mathrm{wks}$ \\
\hline \multicolumn{4}{|l|}{$\%$ B intermedius } \\
\hline Metro + Mech & $15.8(40)^{\mathrm{P}}$ & $3.4(40) \dagger$ & $3.1(32) \dagger$ \\
\hline DB Metro + Mech & 10.0 & $2.5(35)$ & $5.9(22)$ \\
\hline DB Placebo + Mech & $9.6(51)$ & $4.5(51)$ & $8.6(32)$ \\
\hline \multicolumn{4}{|l|}{$\%$ B gingivalis } \\
\hline Metro + Mech & $3.8(41)^{P}$ & $0.1(41)^{\mathrm{P}}$ & 1.4 \\
\hline DB Metro + Mech & $5.9^{\mathrm{P}}$ & 0.3 & 0.9 \\
\hline DB Placebo + Mech & 5.8 & 1.4 & 2.0 \\
\hline \multicolumn{4}{|l|}{$\%$ F nucleatum } \\
\hline Metro + Mech & $3.6^{\mathrm{P}}$ & $1.3{ }^{\mathrm{P}}$ & $4.2^{P}$ \\
\hline DB Metro + Mech & 3.4 & 3.0 & $\overline{9.8}^{\mathrm{p}}$ \\
\hline DB Placebo + Mech & 4.6 & 4.5 & 3.0 \\
\hline \multicolumn{4}{|l|}{$\%$ Veillonella } \\
\hline Metro + Mech & 2.4 & 0.9 & 1.9 \\
\hline DB Metro + Mech & 3.2 & 1.4 & 4.1 \\
\hline DB Placebo + Mech & 1.7 & 2.8 & 1.7 \\
\hline \multicolumn{4}{|l|}{$\%$ A odontolvticus } \\
\hline Metro + Mech & 2.0 & $4.0^{\mathrm{P}}$ & $0.6^{\mathrm{P}}$ \\
\hline DB Metro + Mech & $1.3^{\mathrm{p}}$ & 1.7 & $2.9^{\mathrm{P}}$ \\
\hline DB Placebo + Mech & 0.4 & 2.0 & 0.3 \\
\hline
\end{tabular}

or microaerophilic species is shown in Table 4. Metronidazole should not affect these organisms so that a proportional increase would be expected. This was particularly evident in the case of $S$ mutans and $S$ sanguis, but less evident in $A$ viscosus and $A$ naeslundii and not observed in the case of the Capnocytophaga species (Table 4). Some of this increase was due to the mechanical treatment, as proportional increases were observed in the placebo plus mechanical group, especially in the proportions of $S$ sanguis. The proportions of $A$ viscosus, $S$ sanguis and $S$ mutans declined with time posttreatment. Nevertheless the proportions of $S m u$ tans were still elevated from baseline values some 15 to 30 weeks after metronidazole treatment (Table 4).

Spirochetes comprised about $35 \%$ of the organisms in these plaque samples (Table 5). Their proportions decreased in all treatment groups, but significantly so only in the metronidazole groups. Fifteen to 30 weeks after medication, the metronidazole groups still exhibited about a $50 \%$ reduction in spirochetes, but the placebo group had returned to pretreatment values.

The spirochetes were differentiated into large, intermediate and small sizes. Metronidazole significantly reduced the proportions of large spirochetes in both groups, often to undetectable levels for the entire period of observation. The mechanical treatment reduced the proportions of the large spirochetes initially, but then

\begin{tabular}{|c|c|c|c|}
\hline \multirow{2}{*}{ Treatment regimen* } & \multirow{2}{*}{$\begin{array}{l}\text { Pretreat- } \\
\text { ment }\end{array}$} & \multicolumn{2}{|c|}{ Posttreatment } \\
\hline & & $0-2$ wks & $15-30$ wks \\
\hline \multicolumn{4}{|l|}{ \% Capnocytophaga } \\
\hline Metro + Mech & $1.0(40) \dagger$ & $0.9(40) \dagger$ & $1.4(32) \dagger$ \\
\hline DB Metro + Mech & $4.6 \quad(35)$ & $4.0(35)$ & $3.0(22)$ \\
\hline DB Placebo + Mech & $1.4 \quad(51)$ & $1.8(51)$ & $2.4(32)$ \\
\hline \multicolumn{4}{|l|}{$\%$ A viscosus } \\
\hline Metro + Mech & 0.7 & 2.0 & 0.9 \\
\hline DB Metro + Mech & 2.7 & 5.3 & 2.3 \\
\hline DB Placebo + Mech & 2.2 & 3.9 & 2.9 \\
\hline \multicolumn{4}{|l|}{$\%$ A naeslundii } \\
\hline Metro + Mech & 0.02 & 0.5 & 2.0 \\
\hline DB Metro + Mech & 0.3 & 0.3 & 2.5 \\
\hline DB Placebo + Mech & 0.3 & 1.3 & 0.2 \\
\hline \multicolumn{4}{|l|}{$\% S$ sanguis } \\
\hline Metro + Mech & $4.1^{P}$ & $15.3^{P}$ & 6.8 \\
\hline DB Metro + Mech & 2.0 & 14.1 & 1.9 \\
\hline DB Placebo + Mech & 2.3 & $9.2^{\mathrm{p}}$ & 1.5 \\
\hline \multicolumn{4}{|l|}{$\% S$ mutans } \\
\hline Metro + Mech & 0.2 & 1.1 & 0.5 \\
\hline DB Metro + Mech & 0.4 & 17.7 & 5.3 \\
\hline DB Placebo + Mech & 0.1 & 1.8 & 0.1 \\
\hline
\end{tabular}

${ }^{*}$ Metro $=$ metronidazole; Mech $=$ mechanical; $\mathrm{DB}=$ doubleblind.

$\dagger$ Number of plaque samples involved in paired comparison.

$\mathrm{P}=$ paired $t$ test; values containing these superscripts or $\square$ are significantly different from other values in row. 
there was a rebound at the 15 to 30 -week visit (Table 5).

All treatments significantly reduced the proportions of intermediate size spirochetes, but this reduction only persisted in the patients known to have received metronidazole. Metronidazole significantly reduced the proportions of small spirochetes, whereas only slight reductions were observed in the placebo group (Table 5).

The effect of the treatments on other morphotypes that could be distinguished on darkfield microscopy are presented in Table 6 . All treatments caused an immediate increase in cocci, but this increase was only sustained in the known metronidazole patients. The selenomonads decreased in the metronidazole groups whereas the fusiforms increased in these patients. There was a significant transient increase in rods in the known metronidazole patients.

Between-group comparisons were limited to the participants in the double-blind study who were present for both clinical measurements (Figs. 1 and 2). Prior to treatment these two groups were balanced in terms of suspected periodontopathic organisms such as $B$ gingivalis, $B$ intermedius, $F$ nucleatum, $A$ viscosus, $A$ naeslundii and the various spirochetes (Table 7). The patients destined to receive metronidazole had significantly higher proportions of Veillonella, Capnocytophaga species and $S$ mutans.

Zero to 2 weeks after completion of treatment with either metronidazole or placebo there were significant

Table 5

Effect of Metronidazole or Placebo Plus Mechanical Debridement on Subgingival Proportions of Spirochetes; Microscopic Examination

\begin{tabular}{|c|c|c|c|}
\hline \multirow[b]{2}{*}{ Treatment regimen* } & \multirow[b]{2}{*}{$\begin{array}{l}\text { Pretreat- } \\
\text { ment }\end{array}$} & \multicolumn{2}{|c|}{ Posttreatment } \\
\hline & & $0-2$ wks & $\begin{array}{l}15-30 \\
\text { wks }\end{array}$ \\
\hline \multicolumn{4}{|l|}{$\%$ Spirochetes } \\
\hline Metro + Mech & 37.8 & $4.7{ }^{\mathrm{P}}$ & 17.9 \\
\hline DB Metro + Mech & 37.8 & $6.8{ }^{\mathrm{P}}$ & 19.6 \\
\hline $\begin{array}{l}\text { DB Placebo + Mech } \\
\% \text { Large spirochetes }\end{array}$ & 31.7 & 17.6 & 31.2 \\
\hline Metro + Mech & $3.5{ }^{\mathrm{P}}$ & 0 & 1.0 \\
\hline DB Metro + Mech & $5.0{ }^{\mathrm{P}}$ & 0.7 & 0.6 \\
\hline $\begin{array}{l}\text { DB Placebo + Mech } \\
\% \text { Intermediate spirochetes }\end{array}$ & $4.3^{P}$ & $1.1^{P}$ & 11.5 \\
\hline Metro + Mech & $19.8{ }^{\mathrm{P}}$ & 1.1 & 4.9 \\
\hline DB Metro + Mech & 7.8 & $0.7]^{P}$ & 8.1 \\
\hline $\begin{array}{l}\text { DB Placebo + Mech } \\
\% \text { Small spirochetes }\end{array}$ & $8.8^{\mathrm{P}}$ & $2.2^{\mathrm{P}}$ & 7.0 \\
\hline Metro + Mech & 14.7 & $3.6{ }^{\mathrm{P}}$ & 8.7 \\
\hline DB Metro + Mech & 23.6 & $5.5{ }^{\mathrm{P}}$ & 11.1 \\
\hline DB Placebo + Mech & 19.5 & 15.5 & 14.3 \\
\hline
\end{tabular}

${ }^{*}$ Metro = metronidazole; Mech = mechanical; $\mathrm{DB}=$ doubleblind.

$\mathrm{P}=$ paired $t$ test; values containing these superscripts or $\square$ are significantly different from other values in row.
Table 6

Effect of Metronidazole and/or Mechanical Debridement on Subgingival Organisms; Microscopic Examination

\begin{tabular}{|c|c|c|c|}
\hline \multirow{2}{*}{ Treatment regimen* } & \multirow{2}{*}{ Pretreatment } & \multicolumn{2}{|c|}{ Posttreatment } \\
\hline & & $0-2$ wks & $15-30 \mathrm{wks}$ \\
\hline \multicolumn{4}{|l|}{$\%$ Selenomonads } \\
\hline Metro + Mech & 4.5 & 2.0 & 7.2 \\
\hline DB Metro + Mech & 10.8 & $2.3{ }^{\mathrm{P}}$ & 3.8 \\
\hline DB Placebo + Mech & 5.0 & 4.8 & 6.0 \\
\hline \multicolumn{4}{|l|}{$\%$ Motile rods } \\
\hline Metro + Mech & 4.9 & 3.2 & 3.2 \\
\hline DB Metro + Mech & $4.6^{P}$ & $2.0^{P}$ & 3.4 \\
\hline DB Placebo + Mech & 7.1 & 6.2 & 4.3 \\
\hline \multicolumn{4}{|l|}{ \% Fusiforms } \\
\hline Metro + Mech & 6.4 & 9.5 & 8.5 \\
\hline DB Metro + Mech & 4.8 & $5.1^{\mathrm{P}}$ & $8.0^{P}$ \\
\hline DB Placebo + Mech & 7.7 & 6.3 & 9.1 \\
\hline \multicolumn{4}{|l|}{$\%$ Rods } \\
\hline Metro + Mech & $24.5^{P}$ & $49.0^{\mathrm{P}}$ & 36.4 \\
\hline DB Metro + Mech & 26.2 & 25.7 & 38.3 \\
\hline DB Placebo + Mech & 28.9 & 30.6 & 32.6 \\
\hline \multicolumn{4}{|l|}{$\%$ Cocci } \\
\hline Metro + Mech & $17.7{ }^{P}$ & 30.9 & 32.3 \\
\hline DB Metro + Mech & 16.6 & $56.2^{P}$ & 18.5 \\
\hline DB Placebo + Mech & $19.5^{\mathrm{P}}$ & $31.7^{p}$ & 16.4 \\
\hline
\end{tabular}

proportional changes in the plaque flora. The proportions of monitored anaerobes, such as spirochetes (all sizes), $B$ intermedius and Veillonella, decreased significantly in the metronidazole patients relative to the placebo patients, whereas the proportions of $S$ mutans and fusiforms increased significantly.

\section{DISCUSSION}

Several longitudinal studies have demonstrated that the maximal effect of mechanical-surgical procedures on pocket reduction and apparent attachment gain occurs during or shortly after the completion of active therapy. ${ }^{37-42}$ This benefit can be maintained but not necessarily improved by mechanical debridement delivered at 2- to 3-month intervals. ${ }^{38.42}$ If this is so, then a treatment strategy in periodontics should be to optimize the initial beneficial effects by tactics that are safe, effective and cost-efficient. One such tactic would be the judicious usage of antimicrobial agents in patients who are diagnosed as exhibiting an active infection or who are known to be at risk to such an infection.

The rationale behind the usage of antimicrobials in periodontal disease is valid to the extent that periodontal infections are specific infections. ${ }^{16}$ In this case shortterm intensive usage of antimicrobials may suppress the pathogenic flora, so that when the antimicrobial therapy stops, a nondiseased or normal flora may reestablish in the subgingival ecosystem. In the present investigation all patients exhibited elevated proportions 
Table 7

Double-Blind Study: Effect of Metronidazole or Placebo Treatment Superimposed Upon Mechanical Root Planing*

\begin{tabular}{|c|c|c|c|c|c|c|c|c|c|}
\hline \multirow{3}{*}{ Variable } & \multirow{2}{*}{\multicolumn{3}{|c|}{ Pretreatment }} & \multicolumn{6}{|c|}{ Posttreatment } \\
\hline & & & & \multicolumn{3}{|c|}{$0-2$ wks } & \multicolumn{3}{|c|}{$15-30$ wks } \\
\hline & Metro. & & Placebo & Metro. & & Placebo & Metro. & & Placebo \\
\hline No. of Plaques & 25 & & 30 & 22 & & 30 & 23 & & 30 \\
\hline Pocket Depth & $5.2 \mathrm{~mm}$ & & $6.2 \mathrm{~mm}$ & & & & $4.5 \mathrm{mn}$ & & $5.0 \mathrm{~mm}$ \\
\hline Attachment Loss & $5.4 \mathrm{~mm}$ & & $5.0 \mathrm{~mm}$ & & & & $5.1 \mathrm{mn}$ & & $4.8 \mathrm{~mm}$ \\
\hline \multicolumn{10}{|l|}{ Anaerobes } \\
\hline Total Count $\times 10^{6}$ & 39.3 & & 46.4 & 42.4 & $\stackrel{s}{\rightarrow}$ & 11.4 & 20.3 & & 7.6 \\
\hline$\%$ B. intermedius & 6.7 & & 10.2 & 0.8 & $\stackrel{s}{\rightarrow}$ & 4.3 & 5.9 & & 8.4 \\
\hline$\%$ B. gingivalis & 9.4 & & 11.6 & 0.2 & & 2.3 & & 0.9 & 2.0 \\
\hline \% Veillonella & 5.9 & $\stackrel{s}{\rightarrow}$ & 1.5 & 1.5 & $\stackrel{s}{\longrightarrow}$ & 3.5 & 4.1 & & 1.7 \\
\hline$\%$ A. odontolyticus & 0.6 & & 0.3 & 2.6 & & 3.2 & 3.0 & $\stackrel{s}{\longrightarrow}$ & 0.3 \\
\hline$\%$ F. nucleatum & 2.4 & & 3.7 & 1.6 & & 2.8 & 9.8 & $\stackrel{s}{\longrightarrow}$ & 2.9 \\
\hline$\%$ B. melaninogenicus & 4.0 & & 0.8 & 0.2 & & 0.1 & 4.1 & & 0.3 \\
\hline \multicolumn{10}{|l|}{ Facultative/Microaerophilic } \\
\hline$\%$ Capnocylophaga & 2.0 & $\stackrel{s}{\rightarrow}$ & 0.4 & 1.4 & & 1.4 & 3.0 & & 2.4 \\
\hline$\%$ A viscosus & 2.2 & & 1.1 & 5.3 & & 2.7 & 2.3 & & 2.8 \\
\hline$\%$ A. naeslundii & 0.4 & & 0.2 & 0.1 & & 1.8 & 2.5 & & 0.3 \\
\hline$\% S$. sanguis & 2.8 & & 2.1 & 11.4 & & 9.0 & 1.8 & & 2.4 \\
\hline$\% S$. mutans & 2.1 & $\stackrel{s}{\rightarrow}$ & 0.1 & 23.2 & $\stackrel{s \dagger}{\longrightarrow}$ & 2.0 & 5.3 & & 0.2 \\
\hline$\%$ Facultative & 27.9 & & 30.3 & 64.9 & & 55.7 & 46.7 & & 63.3 \\
\hline \multicolumn{10}{|l|}{ Microscopic } \\
\hline Bacteria/HPF & 23.1 & & 20.1 & 8.2 & & 5.2 & 9.9 & & 6.0 \\
\hline$\%$ Spirochetes & 27.3 & & 29.1 & 2.3 & st & 19.1 & 19.6 & & 28.7 \\
\hline$\%$ large & 2.9 & & 3.6 & 0.04 & $\stackrel{s \dagger}{\longrightarrow}$ & 4.8 & 0.6 & $\stackrel{s}{\longrightarrow}$ & 10.9 \\
\hline$\%$ intermediate & 10.8 & & 12.2 & 0.5 & st & 4.3 & 8.1 & & 6.6 \\
\hline$\%$ small & 12.5 & & 15.1 & 1.8 & $\stackrel{s \dagger}{\leftrightarrow}$ & 13.7 & 11.1 & & 13.6 \\
\hline$\%$ Selenomonas & 6.0 & & 4.8 & 3.2 & & 3.9 & 3.8 & & 5.9 \\
\hline$\%$ Motile rods & 4.6 & & 5.0 & 4.3 & & 6.6 & 3.4 & & 4.3 \\
\hline$\%$ Fusiforms & 5.6 & & 8.6 & 7.7 & $\stackrel{\mathbf{s}}{\longrightarrow}$ & 3.5 & 8.0 & & 9.2 \\
\hline$\%$ Rods & 31.3 & & 32.8 & 30.7 & $\rightarrow$ & 30.1 & 38.2 & & 32.6 \\
\hline$\%$ Cocci & & & 20.6 & 49.0 & & 31.4 & 18.5 & & 16.5 \\
\hline
\end{tabular}

* Values connected by $\rightarrow$ are significantly different by Student $t$ test (S), $P=0.05$.

$\dagger$ Signifies that significance $P$ is less than 0.01 .

of spirochetes and BPB in their plaques which permitted us to make a diagnosis of an active anaerobic infection. The patients differed in the number of sites which exhibited clinical morbidity such as pocket depth and attachment loss. It was this extent of morbidity, rather than obvious bacterial changes, that caused us to recognize two types of patients, those with numerous sites of attachment loss (advanced disease), and those with a moderate number of sites (Figs. 1 and 2). The former patients were given metronidazole, whereas the latter were entered into a double-blind study.

The advanced disease patients showed a profound clinical improvement following 1 week of metronidazole and rigorous mechanical debridement (Figs. 1 and 2 ). How much of this was due to the usage of metronidazole and how much to the mechanical debridement cannot be stated, other than to note that two of the patients in this group had, in the past, received complete conventional periodontal therapy and thus might be considered as refractory patients. The bacteriological changes that occurred are consistent with a metronidazole effect as anaerobes such as BPB and spirochetes were suppressed for 15 to 30 weeks (Tables 3 and 5).

Of particular interest in these patients was the apparent increase in attachment that was detected clinically with the probe. If these measurements reflect accurately what is happening at the base of the pocket, then some of the pocket reduction that occurred in these patients occurred at the bottom of the pocket. If so, then x-rays might reflect this change in pocket configuration. Nonstandardized $\mathrm{x}$-rays taken of these patients suggested that the bone levels about some of these teeth did not decrease over time and may have improved (Fig. 3).

The patients assigned to the double-blind study were 
similar to the advanced disease patients in terms of the proportions of spirochetes and BPB in their plaques. The metronidazole clearly suppressed the proportions of these indicator-organisms in the subgingival plaque immediately following medication both relative to pretreatment values and to placebo treatment values (Tables 3,5 and 7). However, at the 15 to 30 week interval, only the proportions of the large spirochetes were still significantly suppressed in the metronidazole group relative to the placebo group (Table 7). This could indicate that the continued suppression of these organisms was contributing to or was responsible for the improved periodontal health in the metronidazole patients, or that the higher proportions of these organisms in the placebo patients were an early indicator of recurrence of an infection. In this regard it should be noted that only a few of the many anaerobic species present in plaque ${ }^{43}$ are identified by our bacteriological approach. Thus unidentified anaerobes such as Eubacterium species and Peptostreptococcal species ${ }^{43}$ should have been suppressed by the metronidazole, but the duration of this suppression is not known.

Metronidazole is not an antiplaque agent. In fact, metronidazole should select for plaque-forming organisms such as $S$ muttans, $S$ sanguis, $A$ viscosus and $A$ naeslundii, because these organisms are microaerophilic and/or facultative. This occurred in the short run for $S$ mutans, $S$ sanguis and $A$ viscosus, but with the exception of $S$ mutans this selection was not evident in plaques removed 15 to 30 weeks after medication.

The patients destined to receive metronidazole initially had low proportions of $S$ mutans, but the proportions were significantly higher than those found in patients destined to receive placebo (Table 7). Metronidazole led to a large proportional increase in $S$ mutans in those plaques removed 0 to 2 weeks after medication, and this increase, while somewhat subdued, was still evident some 15 to 30 weeks after the metronidazole (Table 7). This selection for $S$ mutans was without apparent clinical significance in our patients but does indicate that the usage of metronidazole in caries-active patients might be contraindicated, or that supplemental topical fluoride treatments should be used.

The Capnocytophaga species and $\boldsymbol{A}$ actinomycetemcomitans are also resistant to metronidazole. The levels of the Capnocytophaga species but not their proportions

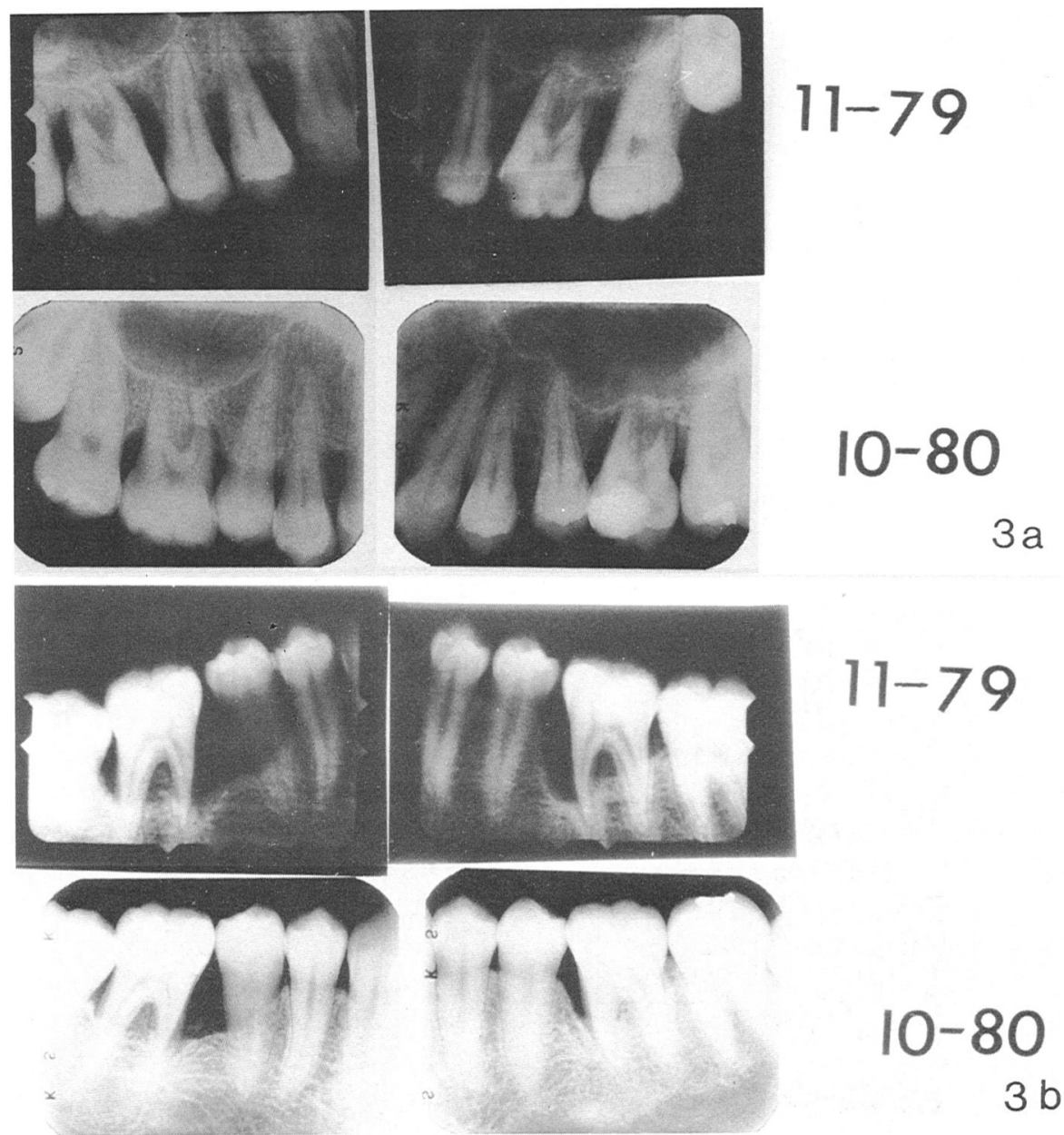

Figure 3. X-rays of 19-year-old patient with generalized bone loss about molars and premolars when seen in November of 1979. Patient was treated for 1 week with metronidazole and had teeth mechanically debrided in November 1979. X-rays taken 1 year later suggest that no further bone loss occurred. The large carious lesion in the upper right first molar was restored. 
increased transiently in the plaques immediately following therapy. A actinomycetemcomitans was not found in these patients either before or after treatment.

At the 15- to 30-week interval, the proportions of certain anaerobes such as $F$ nucleatum, A odontolyticus and Veillonella had increased proportionately in the metronidazole group relative to the placebo group (Table 7). As this increase was associated with a sustained clinical improvement in the metronidazole patients, these anaerobes would appear to be members of the nondisease flora.

The placebo plus mechanical treatment also exhibited some degree of selectivity against anaerobes. Thus the proportions of both $B$ intermedius and $B$ gingivalis (Table 3 ) and total spirochetes decreased initially (Table 5). However this reduction was not sustained. Ongoing studies in our laboratory involving other patients indicated that rigorous mechanical debridement selectively decreases the proportions of BPB and spirochetes. ${ }^{44}$ Thus it may be that nonspecific treatments such as scaling and root planing are successful because in practice they discriminate against anaerobes and select for a facultative flora. If so, then their mechanism of action is comparable to the mechanism of action of metronidazole, i.e. the conversion of a periodontopathic flora to a nondisease-associated flora by the selective deletion of certain anaerobic organisms.

This similarity of mechanism could explain why the metronidazole and placebo treatments were essentially equivalent in the clinical resolution of pockets initially 4 to $6 \mathrm{~mm}$ in depth (Table 1). The mechanical treatment could be delivered at these pocket depths with such effectiveness that only a minimal additional benefit could be derived from the metronidazole. However at pockets greater than $6 \mathrm{~mm}$, the efficacy of mechanical debridement decreases due to instrument inaccessibility of deep root surfaces and furcations. These sites however are apparently bathed by sufficient levels of metronidazole to effect a significant improvement in apparent attachment gain and pocket reduction (Table 1).
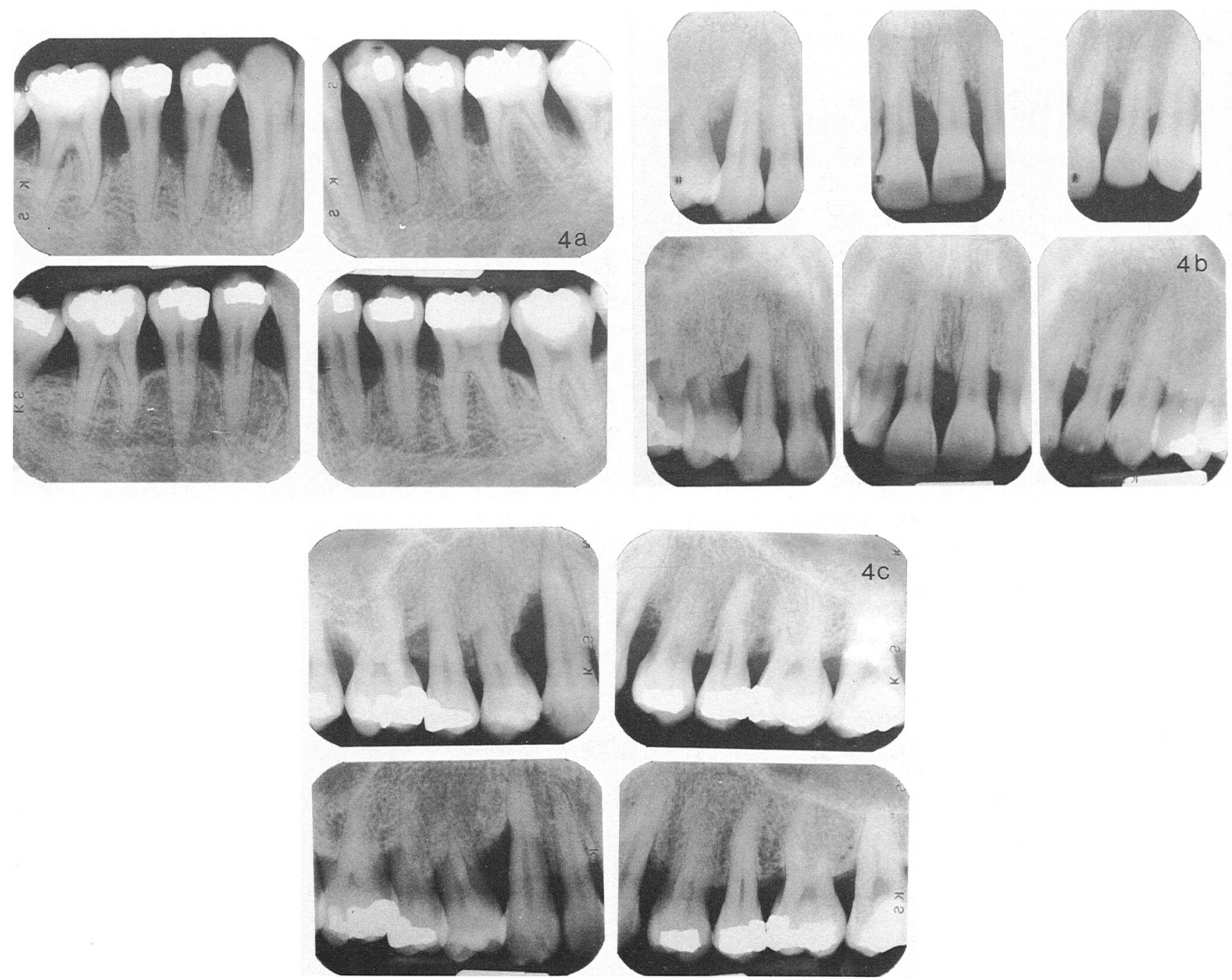

Figure 4. X-rays of 28-year-old patient taken in February 1981 (top row) and in March of 1983 (bottom row). 4a, mandibular teeth, 4b, maxillary anterior teeth, 4c, maxillary teeth. Patient received metronidazole for 1 week and had teeth mechanically debrided in the spring of 1981 . The $x$ rays taken in 1983 suggest that no further bone loss occurred. 
About half of the pocket reduction in these deep pockets in the metronidazole patients was associated with an apparent gain of attachment of about $1.4 \mathrm{~mm}$, whereas in the placebo group the apparent gain in attachment contributed minimally to the pocket reduction (Table 1). This suggests that the metronidazole permitted a type of disease resolution in the base of these deep pockets which was not found with mechanical debridement plus placebo. Again, nonstandardized $x$-rays were suggestive of bone fill about some of the teeth in these patients (Fig. 4). The implication of this finding caused us to terminate the present study and to initiate a second double-blind study in which standardized $\mathrm{x}$-rays would be taken ${ }^{45}$ and then analyzed by subtraction radiography ${ }^{46}$ in order to assess any change in bone levels and/or density.

In conclusion, the results reported in this investigation indicate that short-term usage of systemic metronidazole can optimize the clinical reduction of pockets and increase attachment gain in periodontitis patients who receive concurrent mechanical debridement of their root surfaces. In the case of patients with extensive clinical involvement, the metronidazole treatment results in a significant reduction in the number of sites exhibiting pocket depths and attachment loss $\geq 7 \mathrm{~mm}$. When metronidazole plus mechanical debridement was compared with placebo plus mechanical debridement in a double-blind study, the metronidazole patients exhibited a significant improvement in those sites initially $\geq 7 \mathrm{~mm}$. In both the advanced periodontitis patients and the double-blind patients, the beneficial effect of the metronidazole was associated with a significant and sustained reduction of certain anaerobic organisms such as $B$ gingivalis and the large spirochetes. These data indicate that the periodontal infections present in these patients had a dominant anaerobic component.

\section{REFERENCES}

1. Page, R. C., and Schroeder, H. E.: Periodontitis in Man and Other Animals: A Comparative Review. p 330. Basel, S. Karger, 1982.

2. Löe, H., Theilade, E., and Jensen, S. B.: Experimental gingivitis in man. $J$ Periodontol 36: 177, 1965.

3. Loesche, W. J., and Syed, S. A.: Bacteriology of human experimental gingivitis. II. Effect of plaque and gingivitis score. Infect Immun 21: 830, 1978.

4. Lindhe, J., and Ericsson, I.: Effect of ligature placement and dental plaque on periodonta! tissue breakdown in the dog. $J$ Periodontol 49: 343, 1978.

5. Kornman, K. S., Holt, S. C., and Robertson, P. B.: The microbiology of ligature-induced periodontitis in the cynomolgus monkey. J Periodont Res 16: 363, 1981.

6. Slots, J., and Hausmann, E.: Longitudinal study of experimentally induced periodontal disease in Macaca arctoides. Relationship between microflora and alveolar bone loss. Infect Immun. 23: $260,1979$.

7. Listgarten, M. A., and Hellden, L.: Relative distribution of bacteria at clinically healthy and periodontally diseased sites in humans. J Clin Periodontol 5: 115, 1978.

8. Loesche, W. J., and Laughon, B.: Role of spirochetes in periodontal disease. R. J. Genco and S. E. Mergenhagen (eds), Host-
Parasite Interactions in Periodontal Disease p 62. Washington, DC, American Society for Microbiology, 1982.

9. Slots, J.: Importance of black-pigmented bacteroides in human periodontal disease. R. J. Genco and S. E. Mergenhagen (eds), HostParasite Interactions in Periodontal Disease, p 27. Washington, DC, American Society for Microbiology, 1982.

10. Loesche, W. J., Syed, S. A., Morrison, E. C., et al.: The treatment of periodontal infections due to anaerobic bacteria with short-term treatment with metronidazole. J Clin Periodontol 8: 29, 1981 .

11. Newman, M. G., and Socransky, S. S.: Predominant cultivable microbiota in periodontitis. J Periodont Res 12: 120, 1977.

12. Slots, J., Reynolds, H. S., and Genco, R. J.: Actinobacillus actinomycetemcomitans in human periodontal disease. A cross-sectional microbiological investigation. Infect Immun 29: 1013, 1980.

13. Tanner, A., Haffer, C., Bratthall, G., et al.: A study of the bacteria associated with advancing periodontitis in man. $J$ Clin Periodontol 6: 278, 1979.

14. Mouton, C., Hammond, P. G., Slots, J., and Genco, R. J.: Serum antibodies to oral Bacteroides asaccharolyticus (Bacteroides gingivalis): Relationship to age and periodontal disease. Infect Immun. 31: 182, 1981.

15. Taubman, M. A., Ebersole, J. L., and Smith, D. J.: Association between systemic and local antibody and periodontal diseases. R. J. Genco and S. E. Mergenhagen (eds), Host-Parasite Interactions in Periodontal Disease, p 283. Washington, DC, American Society for Microbiology, 1982.

16. Loesche, W. J.: Chemotherapy of dental plaque infections. Oral Sci Rev 9: 63, 1976.

17. Loesche, W. J.: Dental Caries: A Treatable Infection, pp 558. Springfield, IL, Charles C Thomas, 1982.

18. Listgarten, M. A., and Levin, S.: Positive correlation between the proportions of subgingival spirochetes and motile bacteria and susceptibility of human subjects to periodontal deterioration. J Clin Periodontol 8: 122, 1981.

19. Keyes, P., Wright, W. E., and Howard, S.: The use of phase contrast microscopy and chemotherapy in the diagnosis and treatment of periodontal lesions-initial report. Quint Int Rep 1590: 1, 1978.

20. Shinn, D. L.: Vincent's disease and its treatment. S. Finegold, (ed), Metronidazole, Proceedings of the International Metronidazole Conference, Montreal, Quebec, Canada, May 26-28, 1976. Excerpta Med, 334, 1977.

21. Sutter, V. L., and Finegold, S. M.: In vitro studies with metronidazole against anaerobic bacteria. S. Finegold (ed), Metronidazole, p 279. Exerpta Med, 1976.

22. Loesche, W. J., Syed, S. A., Laughon, B., and Stoll, J.: The bacteriology of acute necrotizing ulcerative gingivitis. $J$ Periodontol 53: 223, 1982.

23. Lindhe, J., Liljenberg, B., Adielson, B., and Borjesson, I.: Use of metronidazole as a probe in the study of human periodontal disease. J Clin Periodontol 10: 100, 1983.

24. Rosenkranz, H. S., and Speck, W. T.: Studies on the significance of the mutagenicity of metronidazole for Salmonella typhimurium. S. Finegold (ed), Metronidazole, Proceedings of the International Metronidazole Conference, Montreal, Quebec, Canada, May 26-28, 1976. Excerpta Med, 119, 1977.

25. Rustia, M., and Shubik, P.: Induction of lung tumors and malignant lymphomas in mice by metronidazole. $J$ Natl Cancer Inst 48: $721,1972$.

26. Roe, F. J. C.: Metronidazole: tumorigenicity studies in mice, rats, and hamsters. S. Finegold, (ed), Metronidazole, Proceedings of the International Metronidazole Conference, Montreal, Quebec, Canada, May 26-28, 1976. Excerpta Med, 132, 1977.

27. Beard, C. M., Noller, K. L., O'Fallon, W. M., et al.: Lack of evidence for cancer due to use of metronidazole. $N$ Engl J Med 301: $519,1979$.

28. Friedman, G. D., and Urg, H. K.: The initial screening for 
carcinogenicity of 53 commonly used drugs. $J$ Natl Cancer Inst 65: 723. 1980.

29. Morgan, I. F. K.: Metronidazole treatment in pregnancy. Int $J$ Gynaecol Obstet 15: 501, 1978.

30. Roe, F. J. C.: Toxicologic evaluation of metronidazole with particular reference to carcinogenic, mutagenic and teratogenic potential. Surgery 93: 158, 1983.

31. Syed, S. A., and Loesche, W. J.: Survival of human dental plaque flora in various transport media. Appl Microbiol 24: 638, 1972.

32. Syed, S. A., Svanberg, M., and Svanberg, G.: Predominant cultivable flora of gingivitis associated plaque of beagle dogs. $J$ Periodont Res 15: 123, 1980.

33. Laughon, B. E., Syed, S. A., and Loesche, W. J.: Rapid identification of Bacteroides gingivalis. J Clin Microbiol. 15: 345, 1982.

34. Laughon, B. E., Syed, S. A., and Loesche, W. J.: API ZYM system for identification of Bacteroides sp Capnocytophaga sp. and spirochetes of oral origin. J Clin Microbiol 15: 97, 1982.

35. Kornman, K. S., and Loesche, W. J.: New medium for isolation of Actinomyces viscosus and Actinomyces naes/undii from dental plaque. J Clin Microbiol 7: 514, 1978.

36. Ramfjord, S. P., Knowles, J. W., Nissle, R. R., et al.: Longitudinal study of periodontal therapy. J Periodontol 44: 66, 1973.

37. Ramfjord, S. P., Knowles, J. W., Nissle, R. R., et al.: Results following three modalities of periodontal therapy. $J$ Periodontol 46: 522. 1975.

38. Knowles, J. W., Burgett. F. G., Nissle, R. R., et al.: Results of periodontal treatment related to pocket depth and attachment level. Eight years. J Periodontol 50: 225, 1979.

39. Pihlstrom, B. L., Ortin-Campos, C., and McHugh, R. B.: A randomized four-year study of periodontal therapy. J Periodontol 52: $227,1981$.

40. Rosling, B., Nyman, S., Lindhe, J., and Jern, J.: The healing potential of the periodontal tissues following different techniques of periodontal surgery in plaque-free dentitions-2 yr. J Clin Periodontol 3: 233, 1976.

41. Lindhe, J.: Treatment of localized juvenile periodontitis. R. J. Genco and S. E. Mergenhagen (eds), Host-Parasite Interaction in Periodontal Disease, p 382. Washington, DC, American Society for Microbiology, 1982.

42. Lindhe, J., Westfelt, E., Nyman, S., et al.: Healing following surgical/nonsurgical treatment of periodontal disease. A clinical study. J Clin Periodontol 9: 115, 1982.

43. Moore, W. E. C., Holdeman, L. V., Smibert, R. M., et al.: Bacteriology of severe periodontitis in young adult humans. Infect Immun 38: 1137, 1982.

44. Syed, S. A., Morrison, E. C., Loesche, W. J., and Ramfjord, S. P.: Bacterial flora of treated periodontal pockets (Abstr. 76). Osaka, Annual Meeting Int/Am Dent Res 1980.

45. Duckworth, J. E., Judy, P. F., Goodson, J. M., and Socransky, S. S.: A method for the geometric densitometric standardization of intraoral radiographs. J Periodontol 54: 435, 1983.

46. Webber, R. L., Ruttimann, V. E., and Grondahl, H.: X-ray image subtraction as a basis for assessment of periodontal changes. $J$ Periodont Res 17: 509. 1982.

Send reprint requests to: W. J. Loesche, Professor of Dentistry and Microbiology, University of Michigan School of Dentistry, Ann Arbor, MI 48109.

\section{In Memoriam}

\section{Frank M. Wentz 1917-1984}

Dr. Frank Wentz, 67, a life member of the Academy of Periodontology, passed away January 8, 1984.

Dr. Wentz received his DDS degree from Temple University in 1939, his Masters degree in dental histology in 1948 and his $\mathrm{PhD}$ in anatomy and pathology in 1954 from the University of Illinois. He embarked on an academic career which spanned 30 years of outstanding accomplishments in periodontics. Clinical application of biologic information was the subject of most of his many scientific articles and numerous textbook contributions.

The measure of Dr. Wentz's enthusiasm for knowledge and universal curiosity was manifest in 1977 when he was stricken with an undiagnosed disease which left him paralyzed. He perceived the disability as just another challenge to be conquered and proceeded with his productive career in teaching, administration and scholarly pursuits. 